\title{
Market Capacity Assessment for Educational Services
}

\author{
Galina A. Kalugina \\ Moscow Aviation Institute (MAI), Volokolamskoe Highway, 4, 125993, Moscow, Russia
}

\begin{abstract}
Based on the studies, in this article there are the main methods for the market capacity assessment and their critical analysis. Based on the identification of specific features of the educational services market, the author proposed adaptation of the methods for determining its capacity. When considering the content of the stages of calculating market capacity, there is a system of basic indicators of quantitative and qualitative assessment and the most representative information sources.
\end{abstract}

Keywords - aerospace industry, educational services, market capacity, national and world markets, services market

\section{Introduction}

No branch of the country's economy can successfully function and develop without highly qualified staff. The problem of training specialists capable of solving complex technical, organizational and economic problems, and improving their qualifications is the most relevant for high-tech industries, which include the aircraft industry and civil aviation [1].

Higher educational institutions providing training should clearly focus their activities on meeting the needs of employers, identify target consumers, and study their specific requirements for specialists of a certain specialization [2].

DOI: 10.18421/TEM93-55

https://doi.org/10.18421/TEM93-55

Corresponding author: Galina A. Kalugina,

Moscow Aviation Institute (MAI), Moscow, Russia.

Email: gakalugina@mail.ru

Received: 27 May 2020.

Revised: 10 August 2020.

Accepted: 16 August 2020.

Published: 28 August 2020.

(cc) BY-NC-ND(C) 2020 Galina A. Kalugina; published by UIKTEN. This work is licensed under the Creative Commons Attribution-NonCommercial-NoDerivs 4.0 License.

The article is published with Open Access at www.temjournal.com
In the processes of globalization and integration of Russia into the world economic community, it is necessary to analyze both domestic and foreign markets. This requires, first of all, an assessment of the capacity of national markets and the search for possible target segments, which is absolutely necessary for working in highly competitive markets, which include the educational services.

In this article there are the results of a research and development of possible methodological approach to the quantitative assessment of market potential, which is required for a competent informed choice of strategic alternatives for the development directions of any company, including higher education institutions.

The market of educational services for training specialists for the aerospace industry was chosen as the object of the research. Consideration of the idea and the main elements of the proposed methodological approach is carried out on the example of the activities of the Moscow Aviation Institute (National Research University) (MAI).

The study of the world market of educational services in this area is based both on statistical and actual materials reflected in authoritative foreign sources [3] and on the results of the author's own analysis [4].

\section{Methods}

The issue of market capacity assessment is well enough dealt with in different works [5]. There are a lot of formulations of the concept that do not contradict each other. Summarizing them, we can accept the following definition of market capacity, which most closely reflects the essence of the considered market category [6]. Market capacity is the maximum possible volume of sales of goods (services) at a given price level for a specific period of time, determined both by the size of effective demand and the value of supply [7], [8].

From the definition it follows that the calculation of the market capacity of a particular product can be carried out both through the supply factor and demand.

For the service market, capacity assessment through the supply factor is not fundamental due to 
the specific features of services as a product, one of which is provision and consumption of services at the same time. In this case, demand creates supply, which is focused on meeting the needs of consumers. Market capacity is determined by solvent demand [9], [10].

In general, capacity through the demand factor can be estimated by the following formula:

$$
M C=n \times q,
$$

where

$n$ is the number of consumers of a particular product in a present market,

$q$ is the consumption rate of a present product by one consumer.

The calculation of market capacity through the proposal is the following:

$M C=P+R-E+I-E i+I i+D-G$,

where

$M C$ is the market capacity,

$P$ is the national production of goods in a present country production,

$R$ is the remnant of inventory in warehouses of manufacturers,

$E$ is the export of goods,

$I$ is the import of goods,

$E i$ is the indirect export (goods used in another product and exported abroad),

$I i$ is the indirect import (goods used in another product and imported from abroad),

$D$ is the decrease (inventory reduction at sellers' warehouses),

$G$ is the growth (increase in inventory in the warehouses of sellers).

The service market is not characterized by both inventory and indirect import and export.

The export of services in this case also has no physical meaning, since the submitting by an educational institution of educational services in another country will form the capacity of another regional market. Import can be recognized as the number of students in the territory of a country having, for example, distance learning, according to the programs of a foreign higher educational institution.

Therefore, the formula can be modified:

$$
M C=P+I .
$$

In any approach, the calculation of the indicator can be carried out both in physical and in value terms.

When searching for target segments in the foreign market at the first stage, it seems logical to assess the market capacity in physical terms. Valuation can be carried out by comparing the existing alternatives, after product positioning and developing marketing programs to promote the educational services of the university on the market.

It is proposed to use an indicator of the potential number of students in the question of the natural assessment of the market characteristic under consideration.

The market capacity of any product or service is estimated by the statistics of the retrospective period and is the actual value. Next, there is a need of a forecast of future capacity for the following planning period. This is necessary to determine the possible market share of the company, to develop its market strategy and tactical actions. It allows to most reasonably plan the development of the company in the near and distant future.

When forecasting market potential, factor analysis is assumed. It includes both the identification of the most significant factors that influenced the market capacity in the retrospective period, and the study of the possibility of changing the market situation under the influence of various political, technological, economic, social, and cultural forces in the future. Determining the composition of factors and the strength of their influence on demand depends on the specifics of the market.

Thus, the proposed technique is universal in the procedural part and at the same time requires knowledge of the features of the object, i.e. market research of specific educational services.

\section{Results}

Since the ultimate goal of the study is the choice of alternatives for entering the international market with services for the preparation and training of specialists for the aerospace field, it is proposed to use the procedure consisting of the following steps:

1. Selection of the most promising countries based on the analysis of quantitative and qualitative economic and demographic indicators.

2. Determining the areas for training specialists in demand on the world and individual national markets.

3. Market capacity assessment through demand to determine the feasibility of entering the market of a particular country.

4. Market capacity assessment through supply to compare with the results of the market capacity assessment through demand.

5. Select countries as target segments.

\subsection{Selection of the Most Promising Countries}

Selection of the most promising countries based on the analysis of quantitative and qualitative economic and demographic indicators is necessary to reduce the number of potential target segments in order to 
further market capacity assessment, which is very time-consuming. The main task of it is to identify countries that meet the following requirements:

- Characterized by the stability of the economy and a steadily improving demographic situation;

- Develop the aerospace industry and the airline industry;

- Have a favorable political environment.

It should be noted that Russia, unfortunately, is not a leader in the provision of educational services, nor in the field of aerospace industry and transport. Outstripping the majority of developing regions in the areas under consideration, it has firm positions in the second or third ten countries. In this regard, when choosing target markets, it is necessary to base, first of all, on the real possibilities of a Russian university to compete with local universities that train specialists in the field of aerospace industry and air transport. For this reason, countries that are significantly superior to Russia in these areas should not be considered.

Now we are going to consider the quantitative and qualitative indicators proposed for the selection of perspective markets.

\subsubsection{Quantitative Assessment}

There are a number of demographic, economic and other indices and ratings characterizing the countries of the world. The most significant for solving the problem of choosing countries that are perspective in terms of demand for educational services in the aviation sector are the following:

- Gross domestic product (GDP) per capita;

- Share of education costs of GDP per capita;

- Education index;

- Human development index;

- Industrial development index;

- Aviation industry development index;

- Turnover between countries.

Many of these factors correlate with each other. Nevertheless, it makes sense to evaluate countries for each of them for a more detailed and in-depth study of the issue. Both the country's rating for each indicator and the forecast of the development trend in this direction are important. Countries with very low rates will be unattractive due to low demand. Countries with high rates will also not be attractive enough, because in this case, the market for educational services will be developed and highly competitive.

GDP per capita is a macroeconomic indicator calculated by dividing the market value of all final goods and services per capita. A more accurate indicator is GDP (purchasing power parity) per capita, which characterizes the level of economic development of a country.

Share of education costs from GDP is an indicator published by the CIA and the World Bank. It reflects public investment on education. By its multiplying by the GDP per capita of the country, a specific indicator of the cost of education per capita is obtained, which clearly demonstrates the specific investment in the field of education. The countries with average and high indicator have priority when choosing a country as a target segment. This is due to the fact that the indicator reflects the possibility of receiving investments from the state, including through grants for the population to study in commercial educational institutions.

The next important indicator is the education index, published by the United Nations, presented for 1980-2013, which measures the level of education in the country. It considers the duration and expected duration of education at all levels (primary, secondary, and tertiary education), especially higher (tertiary) education. All data are published on average across the country and by gender. According to this indicator, we can emphasize countries in which education is in demand among the population and its level is acceptable. Countries with a low index can be excluded as not perspectives. An analogue of the index is the Gross Enrollment Ratio (GER) or Gross Enrollment Index (GEI), published by UNESCO. GER indicates a specific level of education in the country, regardless of age. It is expressed as a percentage of the population in the age group corresponding to a present educational level.

Education index is connected with human development index. This is an integral indicator, which is calculated on the basis of many other indicators, including the education index. It demonstrates the average level of development of education, literacy, living standards, and longevity as the main characteristics of the country's human potential.

The most interesting thing is the dynamics of changes in the indices presented above, which is given in the indicated sources by years. It can also be analyzed over a larger period, for example, over the past 10,20 or even 30 years. This is a very useful tool for analyzing the development trends of countries and their populations, especially at the initial stage of country selection when an educational institution enters the global educational services market [11].

Industrial production index, reflects the process in dynamics and allows tracing the decline or rise in production. It is calculated as the ratio of the volume of production in value terms in the current year to the volume of production of the previous year. Since this 
index is a part of the GDP, it often correlates with it. The correlation is most noticeable for industrialized countries.

Aviation industry development index, presented by PriceWaterhouseCoopers ( $\mathrm{PwC}$ ), is used to a more accurate assessment of the country from the point of demand for educational services in the aviation field. The index is based on several categories and subcategories, including many individual indicators. The main ones relate to assessing the value of the industry, its economic component, geopolitical risks, aviation infrastructure, labor resources, and sectoral and tax policies. The index characterizes both the prospects for investing in the country's industry and its size. It correlates with the volume of the labor market in the field of aviation.

Above-mentioned aviation industry development index includes an assessment of the quality of airports and their connectivity. As a criterion, it can be offered the number of airports in the country, airlines, and the size of the aircraft fleet. The aircraft fleet, in turn, can be assessed in certain categories (helicopters, airplanes of various dimensions). Information about it is presented in detail by the Flight Global information resource with the statistics on the volume of airline traffic. International Civil Aviation Organization (ICAO) publishes information on the number of airports and the volume of air traffic in these airports.

Many resources offer data on the volume of exports and imports of various goods by country. This information can be useful, especially in terms of statistics on the export of various aviation products in such areas as large and small-sized aircraft, aviation equipment, and spare parts and components for aircrafts.

Turnover between countries is an important indicator of economic development. It allows to evaluate the export and import of aviation products, which include aircraft of various classes and types, spare parts and components, various equipment, and related products. This information can be found on the website of the International Trade Center and other sources.

\subsubsection{Qualitative Assessment}

In addition to quantitative indicators and indices, it is advisable to evaluate countries by qualitative indicators, such as:

- Political relations with Russia;

- Availability of economic cooperation in the field of aviation;

- Availability of joint projects in the field of aerospace industry;

- Availability of promising orders for products of the aviation industry of Russia;
- Presence of joint training projects and partnerships with Russia in general and with MAI in particular.

Political relations with Russia. Russia maintains diplomatic relations with 189 states. It has the most favorable relations with countries within the Commonwealth of Independent States (CIS), BRICS, and Shanghai Cooperation Organization (SCO). A positive indicator is the presence of a visa-free regime.

In the direction of economic cooperation between countries, it is necessary to consider, first of all, the aerospace industry, as well as cooperation in the military industry as a whole, since MAI trains specialists who are in demand in the field of development, design and creation of aviation military equipment, weapons, air defense systems, rockets and space products industries, aircraft and rocket engines, and rocket technology control systems. The cooperation and contracts for the supply of the above products is an important factor in the development of the aircraft industry in the importing country, since aviation and military equipment require the creation and development of infrastructure. In the long term, many importing countries prefer to train their own specialists, and on a large scale it is easier, cheaper, and strategically more reliable to do it in their own country.

The following factors must also be considered:

- Partnership with foreign universities;

- Joint projects with foreign organizations;

- International training programs and branches abroad;

- Joint training projects and partnerships with Russia in general and with MAI in particular.

\subsection{Determining the Areas for Training Specialists in Demand in the World and the Individual National Markets}

Before determining the market capacity, it is necessary to clearly define the general characteristics of the services with which it is planned to enter the market. According to the duration and the levels of training, it is preferable to adhere to world practice:

- Pre-university training;

- Bachelor's degree;

- Master's degree;

- Retraining and special programs for working specialists.

As directions of training and specialties, it is proposed to single out the main dominant directions for each existing institute (faculty) of the MAI:

- Design of Aviation Equipment. There is a training for engineers for experienced design 
bureaus and research institutes of the aviation industry. Graduates work on the creation of airplanes, helicopters and other aircrafts, researching the issues of aerodynamics, flight dynamics and control, airworthiness and efficiency of aircraft, life support systems, and aircraft equipment.

- Design of Aircraft Engines. Here specialists are being trained to design various types of engines for various aircrafts, as well as to solve related organizational issues, such as industrial safety, standardization, and metrology.

- Automatic and Intelligent Control Systems. Here specialists are being trained to develop control systems, hardware and software of computers, avionics complexes and control systems, instruments and other systems. Theoretical and practical methods and approaches are studied in mathematical problems, electrical engineering, as well as issues of managing high-tech enterprises and innovation management.

- Radio Electronics, Infocommunications and Information Security. There is a training of specialists in the field of radars, radio navigation systems, communication systems, and radio control.

- Engineering Economics. Management, marketing, finance, and human resources are the main directions here.

- Aerospace Engineering. There is a training of engineers and designers, primarily in the space and rocket field.

- Robotic and Intelligent Systems. There is a training of specialists in the development of sophisticated computer technology, partitions, and equipment.

- Information Technology and Applied Mathematics. There is a training of specialists in the field of software development, information and intelligent systems, and mathematical models.

- General Engineering Training. There is a training of engineers and designers in a wide range of areas related to aircraft and rocket science.

- Materials Science and Technology of Materials. There is a training of specialists in the field of materials science, computer-aided design, quality management and other areas.

- Aerospace High Technology and Production. There is a training of specialists in the field of innovative technologies for the design, testing, operation, and repair of aerospace engineering.

\subsection{Market capacity assessment through demand to determine the feasibility of entering the market of a particular country}

The procedure involves the following steps:

Step 1. Definition of specialized organizations in the aerospace industry:

- Organizations for the development and production of aerospace technology;

- Design bureaus;

- Companies developing components and systems;

- Aircraft development and maintenance companies;

- Factories for the production of machinery, components, and spare parts;

- All kinds of commercial organizations in this field.

In addition, it is necessary to consider the enterprises of related industries, in which specialists will also be in demand, but lesser. However, these enterprises occupy a fairly large market volume and create great demand. This includes air transport infrastructure companies: airlines, airports, leasing companies, training centers, certification, and licensing organizations. A separate area is the military component, the assessment of which is more complicated, and demand is possible only in the case of joint projects or the supply of military equipment to the country.

Step 2. A quantitative assessment of the staff potential of specialized organizations, that is, the number of employees. In this direction, in-depth, frequently repeated research is required to obtain accurate information. For an integrated calculation, we can use the averaged data for each type of company. In this case, it will be necessary to rely on the global practice or the practice of the country for which there is such statistical information for a country with a similar level of development of the aerospace industry.

Step 3. Determining the proportion of jobs that can be offered to specialists in each field of study, not necessarily directly to graduates, but also to experienced specialists.

Step 4. Determining the duration of work of employees in the specialty (average for the market or for each type of company). Here we can use statistics for each country and even for each company, adjusting for staff turnover.

Step 5. Calculation of market capacity by the following formula:

$$
\mathrm{MC}=\sum_{\mathrm{q}=1}^{\mathrm{k}} \sum_{\mathrm{s}=1}^{\mathrm{m}}\left(\mathrm{C}_{q} \times \mathrm{N}_{q} \times \mathrm{P}_{q s} \div \mathrm{Y}\right)
$$

where 
$\mathrm{MC}$ is the market capacity;

$C_{q}$ is the number of companies of type $\mathrm{q}$, for $\mathrm{q}$ from 1 to $\mathrm{k}$;

$\mathrm{k}$ is the number of types of companies;

$\mathrm{N}_{q}$ is the average number of specialists in companies of type q;

$\mathrm{s}$ is the specialty, for $\mathrm{s}$ from 1 to $\mathrm{m}$;

$\mathrm{m}$ is the number of specialties (in the case under

consideration - 11);

$\mathrm{P}_{q s}$ is the percentage of specialists in the company

type q for the specialty s;

$\mathrm{Y}$ is the number of years of the average professional experience of specialists [12].

There is the initial data in Table 1., where the rows are the number of companies of various types and the staff, and the columns are the directions of training.
The number of companies indicated is arbitrary, for example. The number of employees is indicated approximate, typical for the industry. The cells of the table will indicate the approximate percentage of specialists in each company for each specialty or on average for the type of company. As an example, a table is given for a suppositive country. Since an integrated assessment is presented, the companies are divided only into types, the share will be distributed among all types of specialists. For example, in various design bureaus for the development of various products (aircraft, engines, components, etc.), graduates of different areas of training are required. Therefore, the shares are distributed in all directions, and the total share for all university specialists will be the highest one for design bureaus.

Table 1. Standard matrix for calculating the market capacitv for educational services

Number of organizations of various kinds in the target market and the standard number of employees

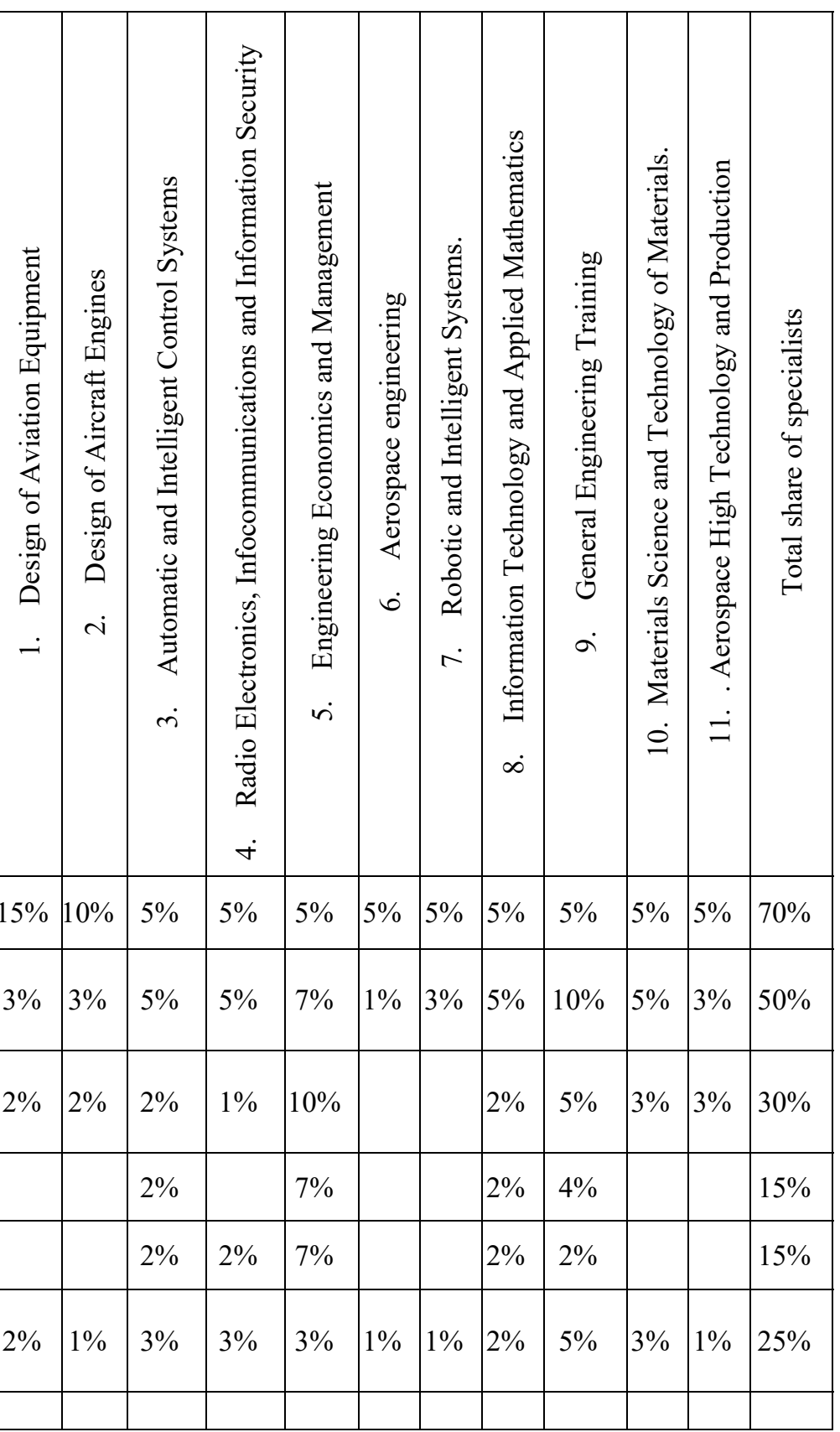


Step 6. Assessment of possible changes in market capacity. Since the initial selection of regional target segments assumed the selection of countries with the prospect of developing the aerospace industry, we can talk about increasing the market capacity. To forecast an increase there, it is proposed to consider the most correlating indicators and factors, which affect the changes:

- Various economic indicators show the number of specialists needed by the aircraft industry (design bureau, manufacturers of aircraft, components, and spare parts). These indicators include GDP, industrial production index, and aviation industry development index;

- For a forecast on the growth of the labor force market in the field of air transportation (for airlines, leasing companies, airports, training centers, and maintenance and repair enterprises of serial civil aviation equipment), we can use the forecast of air transportation of passengers and cargo of the considered country. In this case, the correlation will be higher than in the aircraft industry (especially in the military sector).

\subsection{Market Capacity Assessment Through the Supply}

Market capacity assessment through the supply can be useful for an integrated assessment of the possible market share by expert means, for positioning university services, as well as for solving other marketing problems.

At this stage it is necessary to do the following:

- Determine the list of all educational institutions located in the country;

- Highlight those that have identical or similar specialties;

- Determine, using statistical and reporting data from educational institutions and higher ministries and departments, the number of graduates in these specialties.

To improve the accuracy of calculations, it is advisable to take into account the fact of training of residents of neighboring countries, as well as the outflow of specialists to other countries after completion of training.

The data obtained should be compared with the results of determining the market capacity through demand.

In the case of a slight discrepancy in the calculation results (conditionally up to $30 \%$ ), the data used can be considered reliable, and the calculations are correct.

\subsection{Selection of Countries as Target Segments}

Selection of countries as target segments should be carried out according to the criterion of the largest market capacity, considering the prospects for its growth in the future. So, in addition to analyzing the dynamics of indicators and calculating the potential market capacity, it is necessary to use an expert approach. The final choice should be based on the results of an in-depth study of the country and the market for educational services using marketing tools.

\section{Discussion}

With the development of the Internet, informatization of enterprises, emergence of a large number of audit companies, and information aggregators, companies that create and provide access to various databases, obtaining and using statistical information become easier and cheaper, and the information received is more accurate, relevant, reliable, and complete.

On the example of the object of study considered in the article, the world market of educational services for training specialists for the aerospace industry, a methodological approach to assessing its capacity was proposed, including the following:

- Identification of the main stages of the considering procedure,

- Determination of the totality of factors affecting market capacity,

- Formation of a system of quantitative and qualitative indicators to assess market capacity when making informed decisions on the choice of countries as target segments.

\section{Conclusions}

Using the proposed methodology, it is possible to conduct a much more accurate and in-depth analysis while expanding the range of indicators and their detail.

The study of the world market of educational services in this area is based both on statistical and actual materials reflected in authoritative foreign sources, and on the results of the author's own analysis.

The proposed methodology is universal in the procedural part and can be used to study the market capacity of educational services for various fields. At the same time, the results are especially useful and relevant from a practical point of view for higher education institutions focused on meeting the demand for specialists in the aerospace industries in connection with the specific information of an object nature set forth in the article. 


\section{References}

[1].Vasigh, B., \& Fleming, K. (2016). Introduction to air transport economics: from theory to applications. Routledge.

[2].Hadjar, A., \& Gross, C. (Eds.). (2016). Education systems and inequalities: International comparisons. Policy Press.

[3].Hobbs, J. J. (2016). Fundamentals of world regional geography. Cengage Learning.

[4].UNESCO (2016) Global Education Monitoring Report: Education for People and Planet. Paris: UNESCO.

[5].Danchenok, L. A., \& Laskovets, S. V. (2008). Marketing Management: educational-methodical complex. Moscow: Eurasian Open Institute.

[6].Novikov, S. N., \& Veas Iniesta, D. S. (2018). State regulation of the development of the connectivity of the Russian territory. Revista ESPACIOS, 39(45).
[7].Stubbs, P. C., Tyson, W. J., \& Dalvi, M. Q. (2017). Transport economics (Vol. 21). Routledge.

[8].Spreen, W. E. (2016). Marketing in the international aerospace industry. Routledge.

[9].Holmes, M. (2017). Aerospace looks to composites for solutions. Reinforced Plastics, 61(4), 237-241.

[10]. Green, M. F. (2018). Aviation/Aerospace Teacher Education Workshops: Program Development and Implementation. The Collegiate Aviation Review International, 13(1).

[11]. Ulewicz, R. (2014). Application of servqual method for evaluation of quality of educational services at the university of higher education. Polish Journal of Management Studies, 9, 254-264.

[12]. Sergeieva, L. (2018). Modern professional education and educational services market. Fundamental and applied researches in practice of leading scientific schools, 28(4), 122-126. 